\title{
THE DIGITAL DIVIDE AND ICT LEARNING IN RURAL COMMUNITIES: EXAMPLES OF GOOD PRACTICE SERVICE DELIVERY
}

\author{
Robert Huggins \\ Robert Huggins Associates, Meandros House, 54a Bute Street, Cardiff CF10 5AF, \\ tel: 0292066 2554, fax: 0292046 3067, \\ email: robert@hugginsassociates.com \\ Hiro Izushi \\ Centre for Local Economic Development, Coventry Business School, Coventry \\ University, Priory Street, Coventry CV1 5FB, \\ tel: 02476888421 , fax: 02476888400 , \\ email: h.izushi@coventry.ac.uk
}

\begin{abstract}
This article aims to gain a greater understanding of relevant and successful methods of stimulating an ICT culture and skills development in rural areas. The paper distils good practice activities, utilising criteria derived from a review of the rural dimensions of ICT learning, from a range of relevant initiatives and programmes. These good practice activities cover: (1) community resource centres providing opportunities for 'tasting' ICTs; (2) video games and Internet Cafés as tools removing 'entry barriers'; (3) emphasis on 'user management' as a means of creating ownership; (4) service delivery beyond fixed locations; (5) the use of ICT capacities in the delivery of general services; and (6) selected use of financial support.
\end{abstract}




\section{INTRODUCTION}

Information and Communication Technologies (ICTs) are reshaping the economic and social landscape of people's lives (Castells, 1996; Graham and Marvin, 1996). ICTs have the potential to improve the quality of life of individuals by providing 'easy' access to a wealth of information, goods and services. They can also stimulate continuous innovation that leverages the competitiveness of businesses (DTI, 1998). Yet, there is a growing concern over the digital divide between those who are and are not benefiting from ICTs (DTI, 2000). Lack of ICT access and skills can lead to, or reinforce, disadvantages between individuals and firms at a number of levels (DTI, 2000). For example, it deprives individuals of opportunities to participate fully in the local and national economy. Also, without ICT literate employees and expertise, businesses are unable to compete in the increasingly inter-penetrated global market.

The digital divide in the UK appears to have developed spatially, creating gaps between ICT advanced and lagging areas. According to a DTI survey (1999), there are significant differences in ICT use between core regions and peripheral regions within the UK. Compared with London and South East, a far smaller proportion of firms in peripheral regions, such as the South West, North East, Scotland and Wales, are making use of ICTs. This suggests that firms and individuals, often in rural peripheries, are facing difficulties adapting themselves to the information age and ICTs.

The slow ICT adaptation of rural areas is a cause of concern, as they are already under extreme pressures from an over-reliance on a decreasing agricultural sector, ageing populations, and poor access to services (Martin and McKeown, 1993). Unless there are policy strategies to promote the adaptation to ICTs, the evidence to 
date indicates that market forces will further strengthen existing patterns of uneven development (Grimes and Lyons, 1994). This calls for concerted efforts to build the capacity to utilise ICTs in rural areas.

Awareness of the UK's digital divide has led to the government undertaking a number of high profile initiatives, such as the Information Society programme and the 'IT for All' initiative. Also, the Government has published its own studies and guidance on how ICTs can facilitate improved economic development practices, particularly in deprived areas (DTI, 2000; DETR, 2001). Along with this intervention, a growing number of local initiatives have emerged to facilitate ICT skills development within rural communities (e.g. Astill, 1997; Fraser, 1997).

The aim of this article is to gain a greater understanding of relevant and successful methods for stimulating an ICT culture and ICT skills development in rural areas. Methodologically, we first examined the rural dimensions of ICT learning through a review of the relevant academic literature. This allowed us to obtain three core criteria with which to distil good practices in the delivery of ICT learning programmes. We then examined a total of over 50 programmes identified through academic literature, policy documents and information available on the Internet. Interviews were undertaken with a number of individuals operating ICT learning programmes in the UK, seeking their views as well as in-depth information of the programmes they operate. By means of the distillation criteria, a number of good practices emerged for the analysis.

The structure of the paper is as follows. Section 2 discusses the rural dimensions of ICT learning, while section 3 presents the three criteria obtained, before moving on to discuss good practice activities with regard to the delivery of ICT learning. The paper concludes in section 4 with a summary of the key findings from the study. 


\section{RURAL DIMENSIONS OF ICT LEARNING}

In general, populations in rural areas are dispersed, often isolated, and with relatively poor transportation services provided by at best intermittent or nonexistent public transport networks. Weak public transport infrastructure is a major cause of social exclusion in rural areas, depriving a significant proportion of people of the means of accessing 'places of opportunity' and services (Huggins, 2001). The connection between transport and social exclusion is particularly marked among those who do not have access to private cars, such as unemployed people, families with young children, young people, older people, as well as others with low income (DETR, 2000).

A consequence of a dispersed, and isolated population is the lack of opportunities for accessing new technologies and learning about relevant applications from other users within their community. This is evidenced by the relatively weak performance of rural businesses in innovation and the take-up of new technologies (e.g. Keeble et al., 1992). Rural businesses are generally less innovative and slower to adopt new technologies than their counterparts in more urban locations. With regard to ICTs, some studies suggest a lower level of awareness and utilisation of ICTs, both basic and advanced, in rural areas (e.g. Clark et al., 1995; Berkeley et al., 1996; Smallbone and North, 1999).

This lack of awareness and under-utilisation is, in part due, to the smaller size of businesses and the sectoral distribution of firms skewed towards agriculture and agri-tourism, which have not fully enhanced ICTs as part of their activities (Goddard and Gillespie, 1986; Grimes, 1992; Clark et al., 1995). In addition, the lack of a local industrial and service milieu compounds the problem. In a remote rural business environment there are fewer opportunities for firms to interact with one another, 
compared with urban business environments (Smallbone and North, 1999). Also, while firms involved in business transactions with large and multinational enterprises have more opportunities for creating an ICT learning environment, many rural businesses tend to trade locally, and therefore have a lower propensity for ICT awareness (Goddard and Gillespie, 1986; Berkeley et al., 1996; Smallbone and North, 1999).

As a result of the lack of ICT awareness, rural businesses often fail to take up formal training associated with opportunities to develop new ICT-related business skills and expertise. This leaves most employees reliant upon 'teach-your-self' practices (Johnson and Gubbins, 1992; Huggins, 2001). The lack of formal training is due to the remoteness of rural locations from training providers, and the reluctance of small firm owner-managers to send employees to distant training centres (Smallbone and North, 1999, Huggins, 2001).

As individuals many individuals often first experience ICT activities through their work, a lower take-up of ICTs among rural businesses deprives these people of an important learning opportunity. The situation is likely to be exacerbated in lowincome rural communities, which tend to have a lower rate of economic participation.

In summary, a number of rural dimensions shape the current awareness and application of ICT learning, which is less organised or effective than it is in the majority of urban areas. The situation gives rise to a vicious circle, since the very disadvantages of remoteness and weak public transport infrastructure results in individuals and firms in rural areas - who are those in need of a steady flow and ready access to information through ICTs - being deprived access to the wider 
business and social networks within which ICT learning can be effectively achieved (Fraser, 1997).

\section{GOOD PRACTICE IN THE DELIVERY OF ICT LEARNING}

From the above review of rural dimensions, we drew the following three criteria upon which to distil good practices in the delivery of ICT learning. First, we focused upon how programmes facilitated ICT learning among those with little awareness and knowledge about ICTs. Delivery of ICT learning in rural communities often has to start with quite a low level of ICT awareness and knowledge among target groups. This is compounded by the lack of effective mechanisms for transferring technological knowledge among individuals and firms within rural communities. The criterion established, therefore, consists of the extent to which programmes create demonstration effects within rural communities. The second criterion concerns approaches to overcoming disadvantages that arise from the weak public transport infrastructure in rural areas. It is vital that the delivery of ICT learning reaches out to, and provides access with knowledge and information for, the 'transport poor'. The final criterion established consists of the use of ICT capacities in the delivery of more general programmes and services, as a means of developing an understanding of the wider potential of ICTs. In other words, the means by which ICT learning initiatives are able to reach a wide range of individuals.

These three criteria are not mutually exclusive and often overlap in the programmes we examined. The following sections highlight the good practices that should apply to future programmes aimed at combating digital exclusion in rural areas, and examines them within a thematic framework relevant to these three criteria. The highlighted practices include: (1) community resource centres providing opportunities for 'tasting' ICTs; (2) personal and entertainment activities as tools for 
removing 'entry barriers'; (3) emphasis on 'user management' as a means of creating ownership; (4) service delivery beyond fixed locations; (5) use of ICT capabilities in the delivery of programmes and services; and (6) selected use of financial support.

\section{Community Resource Centres - providing opportunities for 'tasting' ICTs}

Within a rural environment where a significant proportion of individuals and firms have little ICT awareness or knowledge, one of the vital steps any ICT learning programme has to action is to provide a user-friendly environment within which individuals can 'taste' the benefits of ICTs. While Gibbs and Leach (1994) correctly argue that awareness building should be a key component of any ICT policy, Fuller and Southern (1999) further suggest that the provision of advice, information, and awareness raising alone is often problematic, particularly with regard to demonstrating the potential of ICTs. For instance, information provision is only able to describe 'what the technology is' and 'what the functionalities of ICTs are', and often fails to allow individuals to feel and experience the benefits to be derived from the use of ICTs.

In this regard, community resource centres are one of the most important ways to ensure opportunities to taste the benefits of ICTs. Centres facilitating the use of ICTs among individuals in the community first emerged in Scandinavia as 'telecottages' in the late 1980s, undergoing several incarnations since then. Other labels under which they now operate include 'telecentres', 'electronic village halls', 'innovation centres', 'community technology centres', 'IT Hubs', and 'business resource centres'. Technology-based community resource centres provide the vital 
ingredients that people need to 'get going' and 'feel comfortable' with ICTs. In general, community resources centres offer services in the following areas:

- Access - The requirement for public access to ICTs is not going to disappear in the immediate future. Even if they have access to computers in another place such as at home, at work, at school, or at a library, many individuals make use of community resource centres in order to obtain access to better or more powerful computers and particular software applications, or simply to learn about computers (Chow et al., 1998).

- A face-to-face meeting place - Community resource centres provide a faceto-face meeting place among individuals within rural communities. While this consolidates the position of community resource centres as a place of socialising, interactions that take place between different levels of users enhance inter-personal learning and facilitate the development of a milieu.

- Support - Informal assistance and help with new technologies and software is often a vital pre-requisite, particularly among disadvantaged groups. Helpful and knowledgeable staff or volunteers as well as a supportive learning environment are significantly important.

- Learning - Complementing informal support and learning-by-doing, training courses are particularly valuable when they are local, affordable and matched to the needs of local communities.

- Relevant content - Community resources centres not only serve as a place for learning, but they can also create information that is relevant and useful to local communities. Also, through the Internet, they can find other likeminded people situated elsewhere (Making the Net Work, 2000).

Many community resource centres now hold 'taster sessions' to encourage a wider range of people and groups to 'drop in' and 'try out new technology'. An example of this is Warwickshire Rural Enterprise Network (WREN). WREN was one of the UK's first telecottages - the National Rural Enterprise Centre established in 1991 - to provide support for local businesses and communities. WREN runs a series of allday workshops on the use of the Internet for rural voluntary groups. Taking advantage of collaboration and mutual support existing in community groups, such events help to deepen a collective understanding of ICTs amongst the members of the groups. 


\section{Video Games and Internet Cafés: removing 'entry barriers' with personal and entertainment activities}

Good practice examples in the delivery of ICT learning quite obviously involve bridging the gap between the computer literate and those that have no computer skills. Community resource centres should be designed to encourage personal and entertainment elements of the use of ICTs, in order to attract individuals with little or no computer skills. Community resource centres are, more often than not used, for self-directed and self-motivated activities. For instance, a study of community resource centres in the US finds that more than half of centre users come to the centres for such reasons as: finding out about local events and local government; working on personal projects such as editing a newsletter; maintaining a mailing list; or pursuing a personal hobby. Further, playing computer games turned out to be a surprisingly important centre activity for many users (Chow, et al., 1998).

'Internet Cafés' (or 'cyber cafés') are a form of resource centre that has proved effective at attracting individuals, particularly young people. Most usually Internet Cafés are set up with the aim of providing an informal, fun environment for young people, with a focus on new technology. Home working and study support functions often complement a drop-in-space at Internet Cafés. The location of Internet cafés and the ability to attract young people are an especially important issue in rural areas. The Centre for Ottery St. Mary's Internet Café (COSMIC), the rural Internet Café and community technology centre in East Devon, adopts a policy of employing primarily young people. This ensures that the target audience is easily reached, as well as helping to stem the outflow of young people from the area. It is also important to ensure that Internet Cafés are perceived as comfortable environments, where individuals with little or no computer skills can gain experience of new technology, rather than exclusive areas for the recreation of the computer literate. 
However, in operating Internet Cafés or similar types of facilities with entertainment elements, the operator needs to take care to reduce the disruptive behaviour of individuals.

\section{Emphasising 'User Management' - creating the sense of ownership in the learning process}

ICT learning programmes should aim to promote self-help and personal responsibility in the learning process, so that participants feel they 'own' the process and sustain their activities. Therefore, the initial process of attracting individuals needs to be followed up by a stage where novices with little or no computer skills undertake training, and gradually gain knowledge and confidence at their own pace. The Help Us Be Successful (HUBS) initiative in Sussex - a programme managed by an independent association, the Sussex Community Internet Project - aims to bridge the gap between people in disadvantaged communities and the education and employment choices available to them. It starts with informal training involving playing games or learning to use the Internet. However, this is followed by content creation activities, such as word processing, image processing, music composing or web page authoring, on a more regularised basis. With the capability and confidence gained during the early stages, trainees move on to undertaking more formal courses provided by other organisations and institutions. Throughout the course of learning, the HUBS programme encourages its participants to establish times for training firstly on an ad-hoc basis, but progressively in a more structured way, so that they view it as a regular feature of their life. As part of maintaining this regularisation within a rural environment, the programme offers participation at a range of locations, but encourages participants to arrange attendance in advance if possible. 
Similarly, the Warwickshire Increasing Rural Enterprise Development (WIRED) scheme, operated jointly by Warwickshire County Council and WREN, adopts the principle of facilitating self-management by users. WIRED aims to help firms in the sub-region's rural areas access e-commerce capabilities. It offers free on-site ICT consultancy, covering the firm's business process and ICT development requirements, along with training workshops and further subsidised in-depth consultancy. The success of the WIRED scheme is most evident in those firms that have undergone a full cycle of training, advice and development, and whereby the firms themselves have taken a high degree of responsibility for the design of this process. Within this cycle the focus is on (1) grasping the basic principles of ICTs, (2) developing a strategy appropriate for the relevant business type, (3) raising the awareness of staff, and enhancing the general culture and outlook of the business in relation to ICTs, and (4) becoming open to finding business networks and linking to businesses of websites that might be mutually beneficial. Most importantly, firms engaging in this process take responsibility for all of the above. In other words, all the training is 'hands on', and the firms decide the content of the e-commerce site, and learn to manage it. According to the manager of WIRED, it is the 'hiving off' ICTs and Internet services to third parties that leads to the services being misunderstood and improperly implemented, especially in rural areas where there is opportunity for to learn for a range of co-located firms.

\section{Service Delivery Beyond Fixed Locations: supporting the 'transport- poor}

If services are provided at public access points like community resource centres, it is obviously sensible to place them in as convenient a location as possible. This implies that in geographically diverse rural regions there needs to be a number of centres to provide access for all potential users. Given the level of public 
investment required to set up centres this is often problematical within a rural environment (Pfeiffer and Waldron, 1995; Berkeley et al., 1996; Williams, 1997). In order to overcome this problem, and move beyond the traditional delivery of services at fixed locations, a number of successful programmes in rural have incorporated a 'mobile' element to their service delivery mechanisms.

The 'Mobile Advisory Service for Young People', a Prince's Trust-supported project in Nottinghamshire, provides a mobile resource centre that tours outlying rural areas on a regular basis, targeting young homeless people aged 16 and over. This facilitates access to IT-related training and employment schemes among rurallybased young people (Phipps, 1999). Also, COSMIC in East Devon has developed a mobile training facility to complement the training provision at their own training centre, further addressing the rural issues they face.

A similar flexible approach to service delivery is also increasingly found in business support services across rural areas, including the Rural Development Commission's former Business Advice Service (Smallbone and North, 1999). This approach has been adopted by the WIRED scheme operated by Warwickshire County Council and WREN. In the delivery of its diagnosis service, WIRED's consultants undertake onsite visits to determine business processes can be improved by the use of computers, standard office software programmes and the Internet. The visit, which is followed by the design and implementation of action plans, not only ensures a more accurate assessment but also entices those rural firms who are not have the time capacity to travel to advice centres. 


\section{Use of ICT Capacities in the Delivery of Services - demonstrating the benefits of ICTs}

It is important that ICT learning programmes are clearly able to demonstrate the benefits of ICTs within their delivery mechanisms, particularly to those individuals who have little knowledge of their potential. A good example is the use of a suite of laptops by the HUBS initiative in Sussex, which can be connected to the Internet through an ordinary telephone line. This allows HUBS to provide ICT training in any room with a range of community locations, such as a community centre, library, school or other meeting places.

Also, ICTs are increasingly used in programmes providing general-purpose services that are not specifically aimed at ICT training. Such programmes increase the opportunity for individuals and businesses to use ICTs, and deepen the understanding of ICT potential within rural communities. For example, there are a growing number of community networks that aim to connect individuals to other people, as well as information sources within and outside their community. Some programmes, such as RuralNet operated by the National Rural Enterprise Centre, provides services that facilitate individuals and small businesses in rural areas to have an online presence by assisting them in setting up their home pages.

Also a number of local authorities use video conferencing to facilitate remote access enquiries. The Virtual Village initiative, operated by the Nottinghamshire Rural Community Council, installed video conferencing equipment to enable face-to-face access to housing, social services, education, benefits and welfare rights services. These video conferencing links are available at locations such as community resource centres, as well as council-operated 'one-stop shops'. While the use of videoconferencing technologies provides rural communities with remote access to 
relevant services, it also acts as a learning-by-doing facility, familiarising businesses and individuals with new technologies.

\section{Selected Use of Financial Support: breaking down barriers for the disadvantaged}

Within initiatives of the type highlighted above it is undoubtedly necessary that policy-makers and practitioners will need to give consideration to the provision and level of financial support, in order to engage a wider range of rural communities in the ICT learning process. Compared with more densely populated urban areas, delivery of training and business support to rural (and particularly remote rural) firms and individuals will most likely incur additional costs, often referred to as the 'rural premium'. This must be reflected in any performance targets by which programmes (and the advisors or trainers involved) are assessed, as well as in the initial costing of the programme or service itself (Smallbone and North, 1999; Huggins, 2001). However, despite the additional costs of the implementation of these initiatives in rural areas, the majority of training provision programmes reviewed are still offered free of charge to the public and businesses, at least in the initial stages of engagement. As already highlighted, the key ethos behind initiatives aimed at encouraging individuals to embrace new technology for the first time is one of 'breaking down barriers.' Therefore, although the majority of these barriers are concerned with confidence and lack of interest, the cost of participation is an additional barrier, and an initially 'free-service' is usually a necessary feature of ICT learning initiatives in rural areas.

An example of the selected use of financial support is the Penrhyndeudraeth Networked Village, initiated with the support of European funding in 1999, aims to introduce computers into the homes and businesses within the rural area of 
Penrhyndeudraeth in North Wales through the development of an 'online village'. The project offers the residents within the area granted-aided subsidies to purchase a PC and Internet connection, as well as additional support in the form of subsidised telephone bills. One-to-one training courses are also provided at the local village hall. The courses are open to all local residents within the targeted postcode area regardless of whether or not they have invested in the discounted hardware on offer. Evaluation found that the user-group has dramatically expanded its use of ICTs. Use of the Internet and e-mail has trebled during the course of the project, although the group has retained some reluctance to venture into e-commerce. ICT skills within the user-group are now higher than the average across North Wales as a whole.

Initiatives that offer ICT hardware such as PCs for individual households cannot viably offer the service free of charge in the long term. On the other hand, the disadvantaged perceive the costs of hardware, software and telecommunication services as a significant barrier to ICT take-up (DTI, 2000). Therefore, initiatives aimed at improving ICT skills as a means of combating social exclusion should consider the selected use of financial support, such as subsidies - as in Penrhyndeudraeth model - that diminishes progressively over time.

\section{CONCLUSION}

In this paper we first examined the rural dimensions of ICT learning, as a means of identifying criteria with which to distil best practice activities from current ICT learning programmes. Compared with urban locations, rural populations are dispersed, if not isolated, and served by at best intermittent or non-existent public transport networks. The locational conditions, together with the smaller size and the sectoral distributions of firms, not only hampers the development of an industrial 
milieu, but also dampens the willingness of firms to invest in training. Fewer opportunities for using ICTs at home and at work, and a weak milieu for ICT learning, reinforce each other particularly in deprived, low-income and low economic participation rural communities. In view of this, the success of ICT initiatives depends heavily on how to stop this vicious cycle. Those good practice activities we identified aim to: lower barriers to ICT learning and use; stimulate inter-personal learning within communities; and support the 'transport-poor' who lack the means of mobility. Those practices identified cover: (1) the use of community resource centres; (2) targeting of personal and entertainment activities; (3) support of selfmanaged learning; (4) mobile provision of training programmes; (5) demonstration of ICT potential through the use of ICTs in general services; and (6) the selected use of financial support.

The most effective ICT learning provision requires strategies that integrate different programmes into a coherent package at the community level. ICT initiatives should adopt a collaborative approach between relevant organisations, with less protectionism than is often currently the case. Such 'openness' is essential for avoiding an on-going cycle of initiative re-invention. Finally, it is vital to recognise the community sector as an important actor if ICT initiatives are to become sustainable. A key to the success of any ICT programme is the engagement of local communities in the very early stages so that they facilitate the sense of 'ownership' and the development of a self-managed learning process.

\section{ACKNOLWEDGEMENT}

We are grateful to the Mid Wales Partnership for funding parts of this project, in particular the co-ordinating role of Annette Jones, and to Stuart Harries for his input into the original research exercise. 


\section{References}

Berkeley, N., Clark, D., and Ilbery, B. 1996. "Regional variations in business use of information and communication technologies and their implications for policy: case study evidence from rural England." Geoforum 27(1): 75-86.

Castells, M. 1996. The Rise of the Network Society. Oxford: Blackwell.

Chow, C., Ellis, J., Mark, J., and Wise, B. 1998. Impact of CTCNet Affiliates: Findings from a National Survey of Users of Community Technology Centers. The Community Technology Center's Network.

Clark, D., Ilbery, B., and Berkeley, N. 1995. "Telematics and rural businesses: an evaluation of uses, potentials and policy implications." Regional Studies 29(2): 171-180.

DETR. 2000. Social Exclusion and the Provision and Availability of Public Transport. London: Department of the Environment, Transport and the Regions.

DETR. 2001. Using Information and Communications Technology (ICT) to Help Achieve Regeneration Objective. London: Department of the Environment, Transport and the Regions.

DTI. 1998. The 1998 Competitiveness White Paper - Our Competitiveness Future Building the Knowledge Driven Economy. London: Department of Trade and Industry.

DTI. 1999. Moving Into the Information Age: Regional Benchmarking Study. Department of Trade and Industry, London: HMSO.

DTI. 2000. Closing the Digital Divide: Information and Communication Technologies in Deprived Areas. London: Department of Trade and Industry.

Fraser, C. 1997. "Rural economies and ITCs: the Network 2000 project." Local Economy 12(1): 79-81.

Fuller, E.C., and Southern, A. 1999. "Small firms and information and communication technologies: policy issues and some words of caution." Environment and Planning C: Government and Policy 17(3): 287-302.

Gibbs, D., and Leach, B. 1986. "Telematics in local economic development: the case of Manchester." Tijdschrift voor Economische en Sociale Geografie 85: 209-223.

Goddard, J.B., and Gillespie, A.E. 1986. "Advanced telecommunications and regional economic development." Geographical Journal 152: 383-397.

Graham, S., and Marvin, S. 1996. Telecommunications and the City: Electronic Spaces, Urban Places. London: Routledge.

Grimes, S. 1992. "Exploiting information and communication technologies for rural development." Journal of Rural Studies 8: 269-278.

Grimes, S., and Lyons, G. 1994. "Information technology and rural development: unique opportunity or potential threat?" Entrepreneurship and Regional Development 6(3): 219-237.

Huggins, R. 2001. "The skills economy and its development: examples and lessons from a rural region" Policy Studies 22(1): 19-34.

Johnson, S., and Gubbins, A. 1992. "Training in small and medium sized enterprises: lessons from North Yorkshire." in K. Caley, E. Chell, F. Chittenden and C. Mason (eds.) Small Enterprise Development, London: Paul Chapman.

Keeble, D., Tyler, P., Broom, G., and Lewis, J. 1992. Business Success in the Countryside: The Performance of Rural Enterprise. London: The Stationery Office.

Making The Net Work. 2000. "Create centres - overview", available at http://www.makingthenetwork.org.uk.

Martin, W.J., and McKeown, S.F. 1993. "The potential of information and telecommunications technologies for rural development." The Information Society 9(2): 145-156.

Pfeiffer, W.C., and Waldron, M.W. 1995. "Introducing a continuous learning culture for rural communities." Canadian Journal of Agriculture Economics 43(4): 629- 
635.

Phipps, L. 1999. New communications technologies - a conduit for social inclusion. paper presented at Politics \& Internet, 2nd International Congress on Electronic Media \& Citizenship in Information Society, Helsinki and Espoo, 6-9 January.

Smallbone, D., and North, D. 1999. "Innovation and new technology in rural small and medium-sized enterprises: some policy issues." Environment and Planning C: Government and Policy 17(5): 549-566.

Williams, M. 1997. "Local economic and community development: the growing potential for information and communications." Local Economy 12(1): 64-68. 